\title{
Geoelectrical Assessment of Groundwater Potential at Ewuloja and its Environs in Simawa Area, Southwestern Nigeria
}

\author{
L. Adeoti ${ }^{1 *}$, R. B. Adegbola ${ }^{2}$, A. Iya ${ }^{1}$, T. Oyeniran ${ }^{1}$, M. A. Ayuk ${ }^{3}$ \\ ${ }^{1}$ Department of Geosciences, University of Lagos, Akoka, Lagos State, Nigeria. \\ ${ }^{2}$ Department of Physics, Lagos State University, Ojo. Lagos, Nigeria. \\ ${ }^{3}$ Department of Applied Geophysics, Federal University of Technology, Akure, Nigeria.
}

\begin{abstract}
Groundwater potential assessment using the vertical electrical sounding (VES) technique was carried out at at Ewuloja and its environs in Simawa Southwestern, Nigeria with a view to solving the problem of incessant failure of groundwater boreholes in the study area. A total of 40 VES were carried-out using Schlumberger electrode configuration. The data was interpreted quantitatively using the partial curve matching and computer iteration techniques to generate the first order geoelectric parameters. The borehole lithological log was used to constrain the conventional VES interpretation. The VES results aided by the borehole lithological log reveal four to seven distinct subsurface geologic layers which correspond to Top soil, Lateritic clayey sand, Sand, Sandstone and Consolidated sandstone. The analysis shows that sands at the upper layer within the depth of $2.3-76.2 \mathrm{~m}$ are unsaturated while sands at depth not less than $100 \mathrm{~m}$ in some sampling points are saturated and denote the aquifer units in the study area. Boreholes/deep wells could be cited at these points at depth interval $150-210 \mathrm{~m}$. This study has provided an insight to the subsurface condition of the aquifer systems and delineated areas for probable groundwater development in Simawa community.
\end{abstract}

KEYWORDS: Vertical electrical sounding, aquifer, consolidated sandstone, earth resistivity, lateritic clay.

[Received October 2 2017; Revised December 25 2017; Accepted March 24 2018]

\section{INTRODUCTION}

Water is crucial for all life on earth. It plays an essential role in our health, economy, food production, and environment. Despite this importance, water is a finite natural resource. It cannot be created. It is the hydrologic cycle that recycles water through the atmosphere. Twenty-one (21) of the thirty-seven (37) primary diseases in developing countries are related to water and sanitation therefore safe drinking water and freshwater are imperative for development and public health ( World Water Organization, 2010).

Globally, one billion people do not have access to safe water (WHO/UNICEF, 2000). The scarcity of water is more intense in the developing countries where statistics shows that $67 \%$ of the rural population has no access to safe water supply (Rosen and Vincent, 1999). This is so because people in the rural areas tend to depend mostly on surface water (from lakes, streams, ponds and rivers) for their sustenance. Surface water bodies however, are not reliable in that they are associated with high evaporation rates usually in high temperate environments and often susceptible to pollution and waterborne diseases. In order to supply water from these sources particularly for domestic purposes, one requires treatment especially in small settlement communities. In many communities where people cannot afford such treatment, they tend to use these waters as they exist, thus

*Corresponding author's e-mail address: lukuade@yahoo.com resulting in water borne endemic outbreaks, such as guinea worm infection, etc.

Groundwater has been proven to be absolutely free of contaminants, except in few places where they are contaminated due to the presence of elements such as arsenic and other heavy metals or by other sources of compromise such as leachate seeping into the aquifer (Bayewu et al, 2012). Water could be found in either basement or sedimentary terrains. Basement rock lacks a defined primary porosity but possesses secondary porosity with the presence of joints, fracture, fault etc. Most sedimentary rocks serve as good aquifers because they possess primary porosity and their pores spaces are interconnected. These two factors (i.e. the primary porosity and the rock unit permeability) determine whether a unit of rock can serve as a good aquifer.

Electrical resistivity method of geophysical exploration happens to be the most applied method in groundwater exploration (Alabi et al., 2010). This is applied in the 1D mode, (Vertical Electrical Sounding), 2D mode (Constant Separation Traversing (CST) or electrical profiling) and 3D electrical imaging (Loke, 2012).

The Vertical Electrical Sounding (VES) is a geoelectrical method for measuring vertical variations of electrical resistivity due to inhomogeneities in the subsurface. The method has been recognized to be more appropriate for hydrogeological study of sedimentary basin (Iserhiendoi: http://dx.doi.org/10.4314/njtd.v15i2.2 
Emekeme et al., 2004; Alabi et al., 2010). Its wide applicability is associated with the simplicity of instrumentation. Also, the field logistics are easy and straight forward while the analyses of the sets of acquired data are less tedious and economical (Olowofela et al., 2005; Omosuyi et al., 2007; Batayneh, 2009; Ezeh and Ugwu, 2010).

The area under investigation is a fast growing community in terms of population and business activities. It is characterized by the shortage of potable water suitable for domestic and economic purposes. Only two out of ten boreholes drilled primitively in this area produce good quality fresh water while others produce turbid water.

Virtually all the hand dug wells dry up during the dry season which might be due to temporary nature of the aquifers. Thus, there is a great problem of locating prolific aquifers in different parts of the study area. Hence, good quality water source(s) must be found for the residents of this area with a view to saving community from epileptic water supply and unknown health hazards. To address these challenges, Electrical resistivity methods of geophysical prospecting might be very useful.

In this study, the vertical electric sounding using schlumberger array was employed to investigate the groundwater potential at Simawa, Ogun State to assist in planning, improvement and management of the groundwater resource of the area.

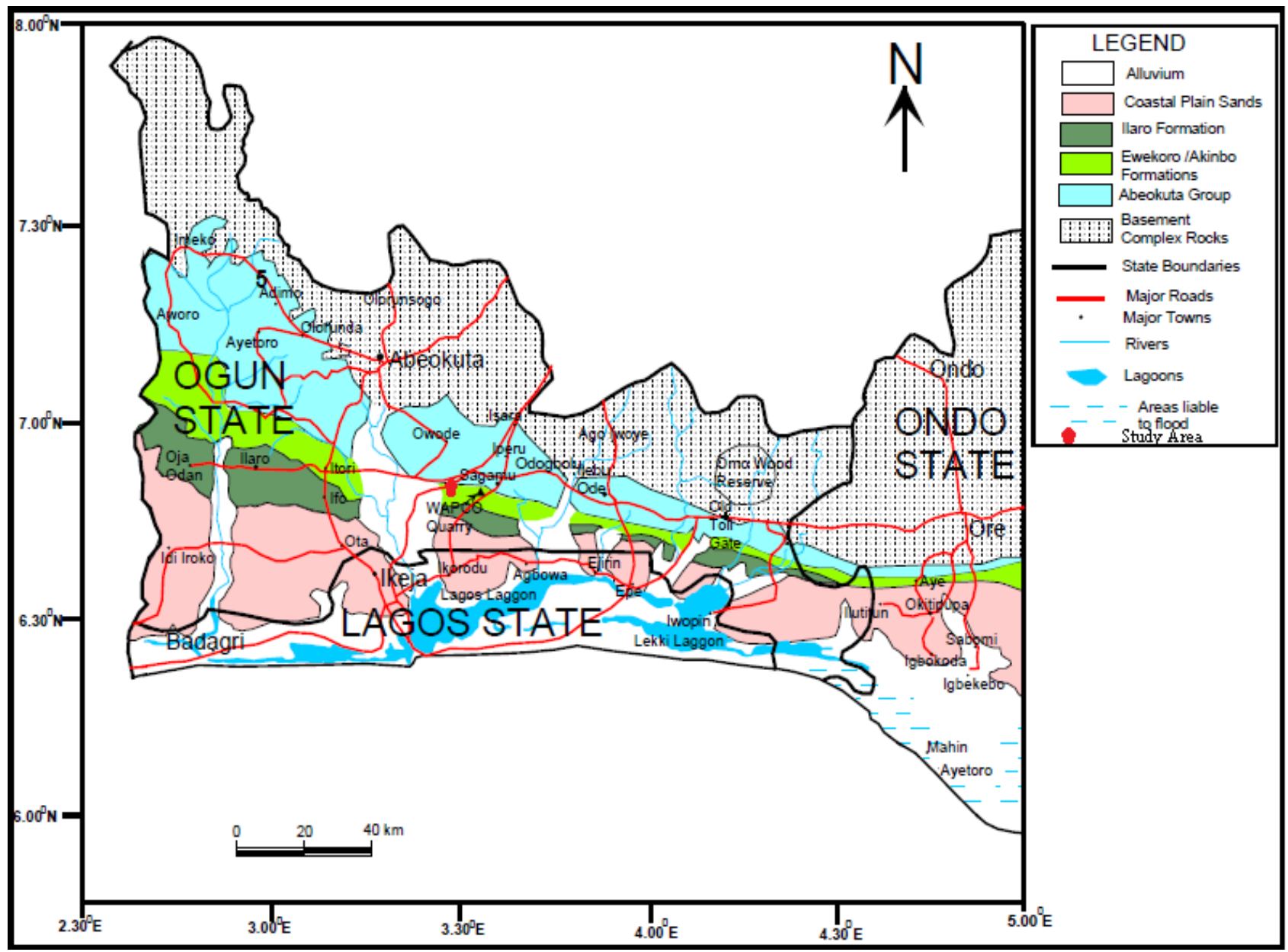

Figure 1: Geological Map of Dahomey Basin in the Nigerian Sector and the States located on the Basin modified after John and Hockey, 1964.

\section{A. Geology of the Study Area}

The study area falls within the Nigeria sector of the Dahomey basin as shown in Figure 1.The stratigraphic units of the Dahomey Basin are composed of the late Cretaceous predominantly sandy strata of the Abeokuta Group as the oldest (Salami and Olorunfemi, 2014).
The overlying Tertiary strata include limestone, of the Ewekoro Formation, shale, of the Akinbo Formation, mudstones/shale of the Oshosun Formation, sandstone of the Ilaro Formation. Other younger strata are the Oligocene to Recent continental sands of the Benin Formation as well as recent alluvial sediments (Omatsola and Adegoke, 1981; Adediran et al, 1991; and Nton et al, 2009). The saturated sandstone, limestone and sandy sediments within these strata constitute the aquifer units. 
The high annual rainfall of the State indicates proper recharge of these aquifer units. The base map of the study

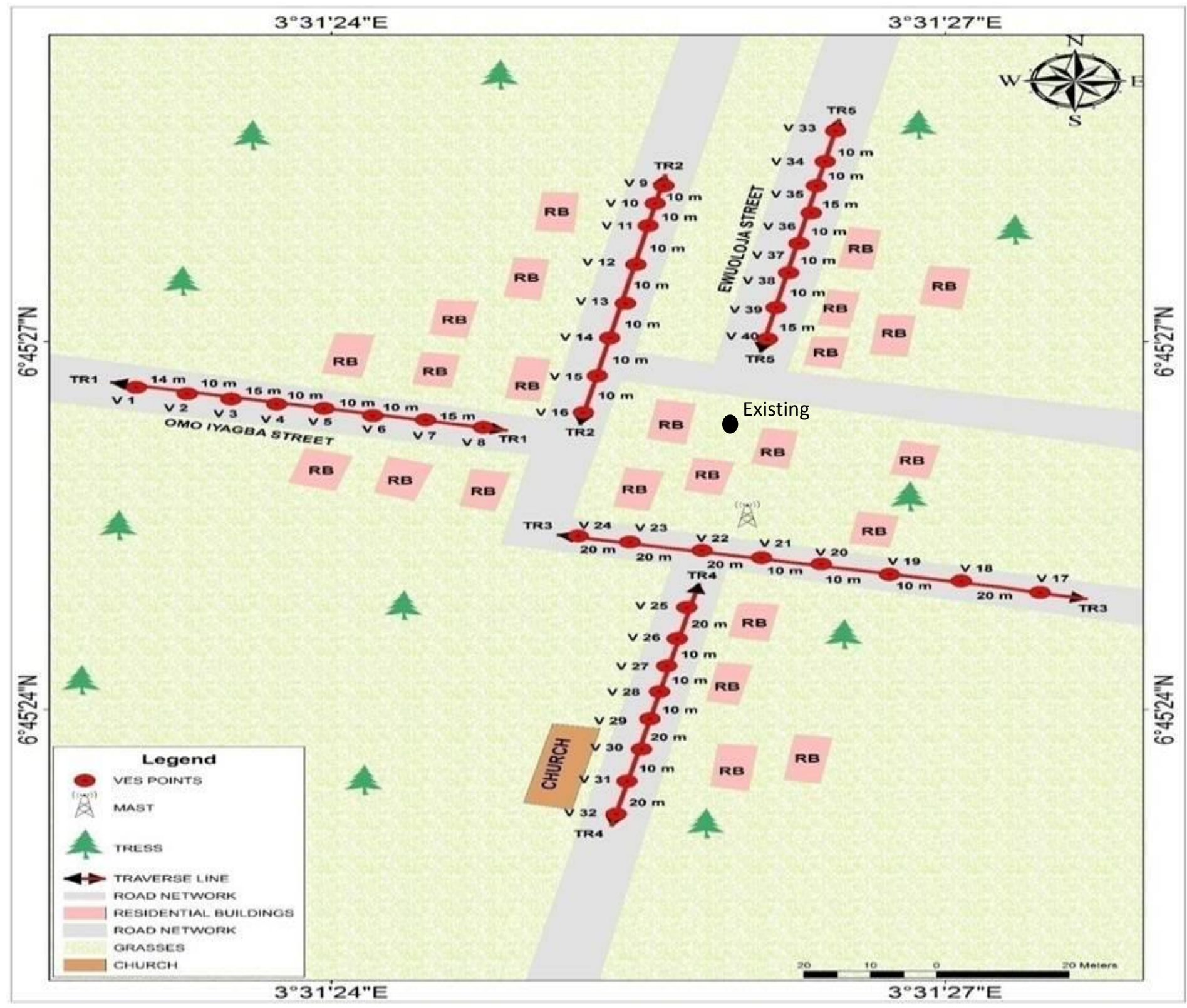

Figure 2: Base map of the Study Area.

\section{METHODOLOGY}

\section{A. Data Acquisition}

PASI earth resistivity meter was used to acquire 40 VES along five tranverses using schlumberger array within the study area (Figure 2). The resistivity meter was powered by $12 \mathrm{Vdc}$ power source. Other ancillary materials/tools used are measuring tape, four (4) hammers and four (4) metal electrodes (with two for current and two for potential). The area showing the sampling points is displayed in Figure 2. 


\section{B. Data Processing and Interpretation}

The processing and interpretation were done both qualitatively and quantitatively. The qualitative interpretation entails observation of the sounding curves as plotted on loglog graph paper. Quantitative interpretation of the VES data was carried out by plotting and smoothing of the apparent resistivity field data curve, the apparent resistivity values measured at each station were manually plotted against half current electrode spacing $(\mathrm{AB} / 2)$ on a $\log$-log graph sheet, using a transparent tracing paper superimposed on the sheet.

The curves obtained for the VES profile were matched with theoretical curves to obtain points of coincidence. These points of coincidence gave the layer parameters used to derive resistivity, thickness and depth values for each layer. Further analysis was carried out on the VES data using the WinResist 1.0 computer software. The software inverts the curve-matched data that best fit the true earth model. The computer modelling program converted apparent resistivity values into true resistivity values in 1-D model curves. Geoelectric section for a group of VES points on each transverse was drawn on the basis of the resistivity data interpretation.

\section{RESULTS AND DISCUSSION}

The samples of VES results are presented as sounding curves in Figure 3(a-e). The geoelectric sections are shown in
Table 1: Borehole Lithological Information.

\begin{tabular}{ccl}
\hline S/N & Depth $(\mathbf{m})$ & Lithology \\
\hline 1 & $0-18$ & Lateritic Clayey Sand \\
2 & $18-29$ & Fine Grained Silty Clay \\
3 & $29-40$ & Fine-Grained Silty Sand with Pebbles \\
4 & $40-41$ & Fine-Grained Clayey Sand \\
5 & $41-73$ & Medium-Fine Grained Sand \\
6 & $73-76.2$ & Clay \\
7 & $76.2-87$ & Fine-Medium Grained Sand \\
8 & $87-88$ & Consolidated Sandstone \\
9 & $88-88.3$ & Fine Grained Clayey Sand \\
10 & $88.3-104$ & Fine-Medium Grained Sand \\
11 & $104-105$ & Consolidated Sandstone \\
12 & $105-108$ & Fine-Medium Grained Sand \\
13 & $108-109$ & Consolidated Sandstone (Fractured Rock) \\
\hline
\end{tabular}

The geoelectric parameters (resistivity, thickness and depth) generated by WinResist were used to initially infer the subsurface lithologies of the study area. This interpretation was constrained by available borehole information (Table 1).

Figures 4 - 8 .

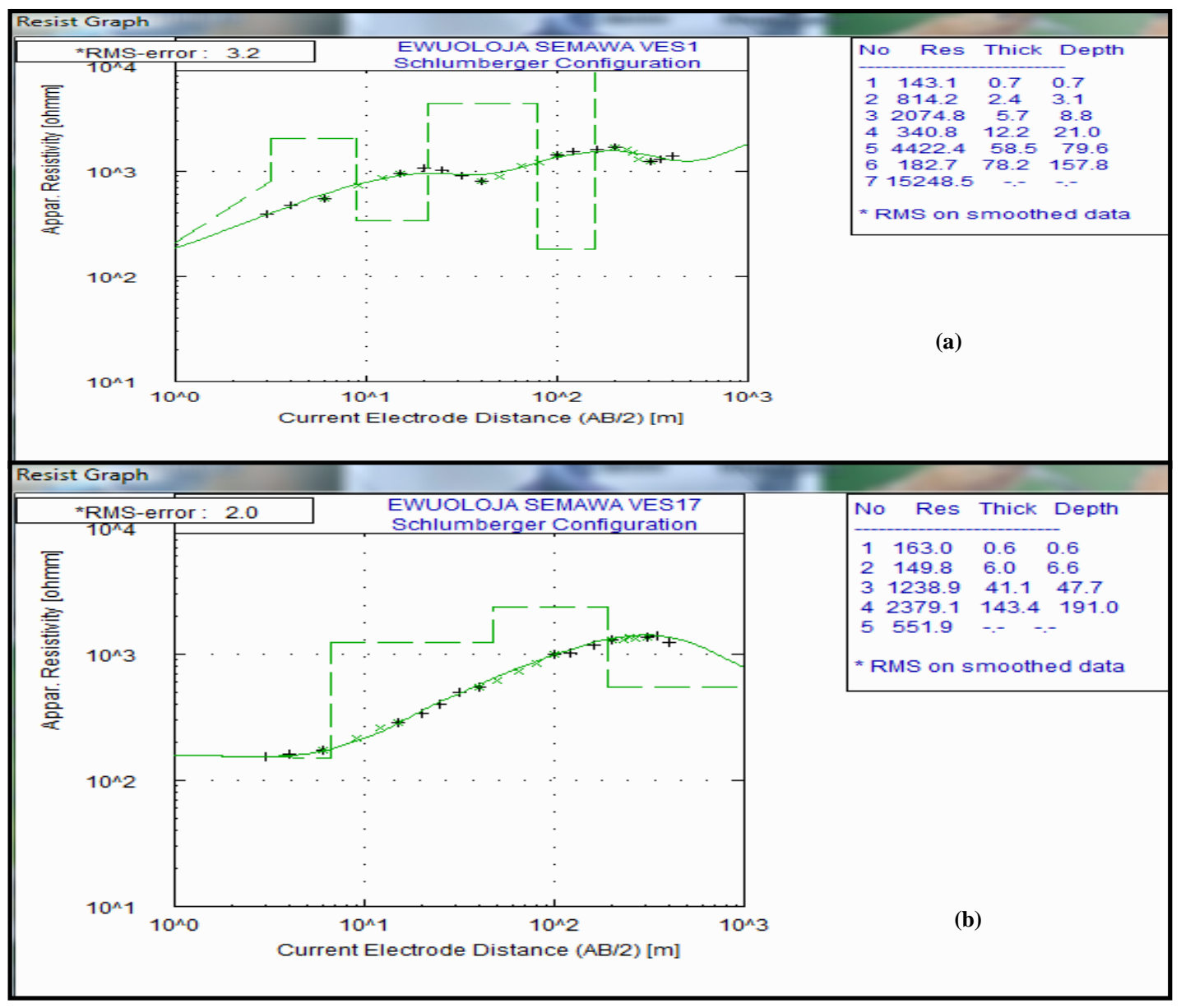



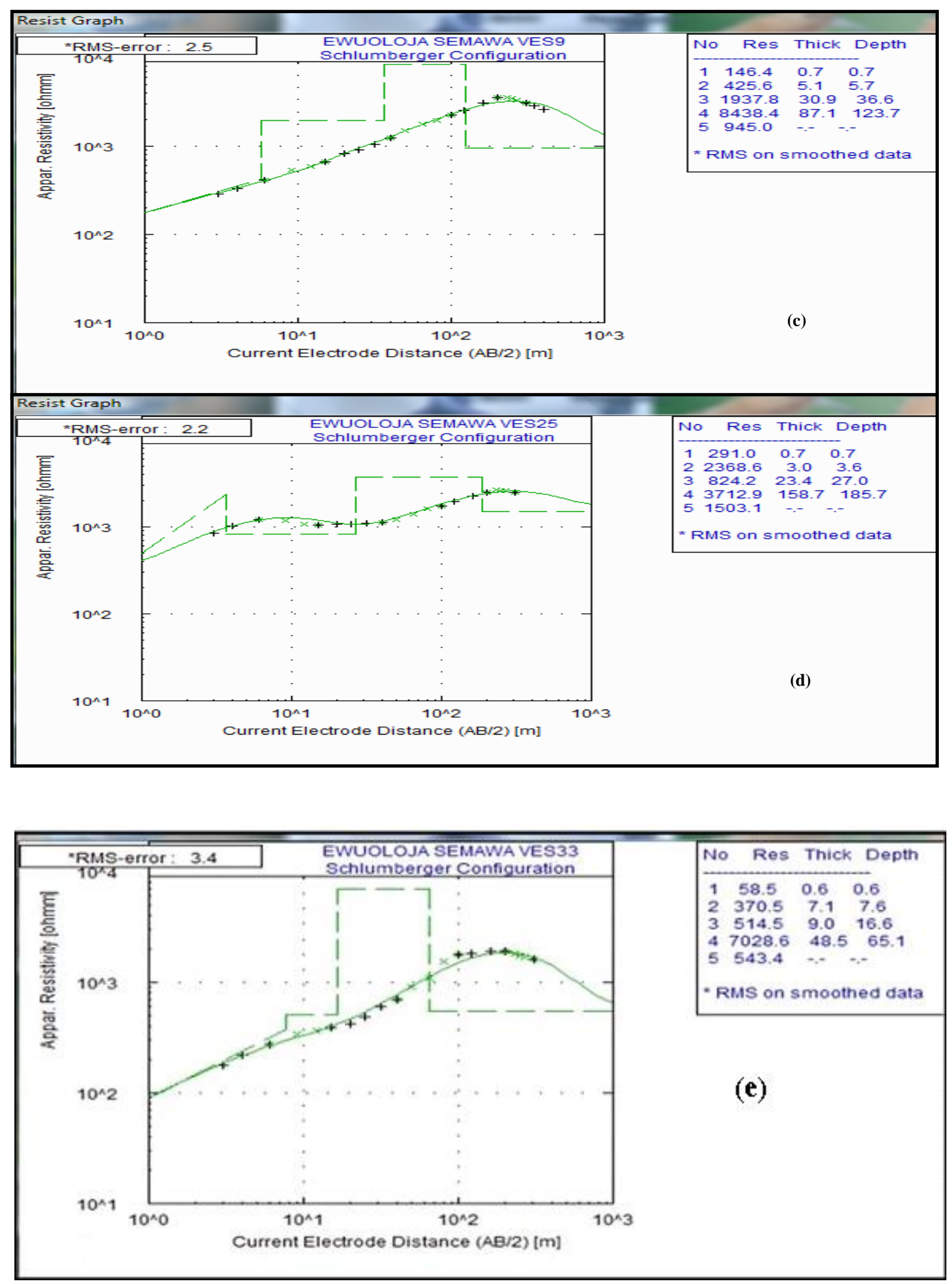

Figure 3: Samples of sounding curves on the five traverses (TRs) (a) TR 1 (VES 1), (b) TR 2 (VES 9). (c) TR 3 (VES 17) (d) TR 4 (VES 25 and (e) TR 5 (VES 33). 


\section{A. Geo-electric Section AA'}

The geoelectric section along AA' contains VES $1-8$ (Figure 4). The configuration of the subsurface is five to seven geo-electric layers. These are topsoil, lateritic clayey sand, sand, sandstone and consolidated sandstone. The first layer (topsoil) has resistivity values range between 68.9 to $329.8 \Omega \mathrm{m}$ and layer thickness 0.5 to $0.8 \mathrm{~m}$. The second geoelectric has sand which has resistivity values ranging between $126.1-814.2 \Omega \mathrm{m}$ and layer thickness of $2.7-4.5 \mathrm{~m}$. The third stratum is characterized by lateritic clayey sand with resistivity 599.2 - $2074.8 \Omega \mathrm{m}$ and layer thickness 3.7$66.2 \mathrm{~m}$.

The fourth layer is sand in VES 1 and 2 with resistivity values of 340.8 and $306.7 \Omega \mathrm{m}$ and layer thickness of 12.2 and $12.4 \mathrm{~m}$. In VES 3, 4, 5, 6 and 7, the fourth layer is sandstone with resistivity values of $1847-3641.7 \Omega \mathrm{m}$ and layer thickness of 65.9 - $144.9 \mathrm{~m}$ while in VES 8 the forth layer depicts consolidated sandstone with resistivity value of $8965.0 \Omega \mathrm{m}$ and layer thickness of $79.8 \mathrm{~m}$.

In VES 1 and in VES 2, the fifth layer is the sandstone and consolidated sandstone respectively. Their resistivity values range from 4422.4 and $6117.2 \Omega \mathrm{m}$ and layer thickness layer thickness of 58.5 and $61.0 \mathrm{~m}$. In VES 3-8, the fifth layer is sand. resistivity value ranges 508.3 to $1332.5 \Omega \mathrm{m}$ with layer thickness of $82.1 \Omega \mathrm{m}$. The thicknesses of this layer in VES 4-8 could not be determined because the current terminated within this zone. This layer denotes possible aquifer in the study with the exception of VES 4 which is symptomatic of dry sand. The sixth geologic unit in VES 1 and VES 2 corresponds to sand. Its resistivity value ranges from 148.9 to $182.7 \Omega \mathrm{m}$ with layer thickness of $62.4-78.2 \mathrm{~m}$.
This can also be a possible aquifer in the study area. The sixth geoelectric layer in VES 3 is diagnostic of sandstone. Its resistivity value is $3585 \Omega \mathrm{m}$ but the layer thickness could not be determined because the current terminated within this zone. The seventh geoelectric layer in VES 1 and VES 2 are consolidated sandstone and sandstone respectively. Their resistivity values are $15248.5 \Omega \mathrm{m}$ and $3817.9 \Omega \mathrm{m}$. The layer thickness within this layer could not be ascertained because the current terminated within this zone.

\section{B. Geo-electric Section BB'}

On geoelectric section BB' are VES 9 - 16 (Figure 5). The subsurface is made up of five to six geoelectric layers. The layers correspond to topsoil, lateritic clayey sand, sand, sandstone and consolidated sandstone. The topsoil is characterized by resistivity values ranging from 76.5 to 219.7 $\Omega \mathrm{m}$ with layer thickness of 0.6 to $1.0 \mathrm{~m}$. The second horizon in VES 9-15 depicts sand with resistivity values ranging from 154.2 to $664.8 \Omega \mathrm{m}$ and layer thickness of 1.3 to $11.1 \mathrm{~m}$. The second layer in VES 16 is lateritic clayey sand with resistivity value 1047.3 and layer thickness $2.7 \mathrm{~m}$.

The third stratum represents lateritic clayey sand with resistivity values ranging from 778 to $2648.2 \Omega \mathrm{m}$ and layer thickness ranging from 3.5 to $42.9 \mathrm{~m}$ while in VES 16, the stratum represents sand with resistivity value of $408.3 \Omega \mathrm{m}$ and layer thickness of $13.7 \mathrm{~m}$. The fourth geoelectric layer represents consolidated sandstone with resistivity values ranging from 4187.9 to $8438.4 \mathrm{ohm}-\mathrm{m}$ and layer thickness of 71.1 to $172.9 \mathrm{~m}$ in VES 9, 12, 13, 14 and 16 while in VES 10 and VES 11 the layer represents sandstone with resistivity values of $3628.9 \Omega \mathrm{m}$ and $2536.8 \Omega \mathrm{m}$ with layer thickness $105.8 \mathrm{~m}$ and $172.9 \mathrm{~m}$ respectively.

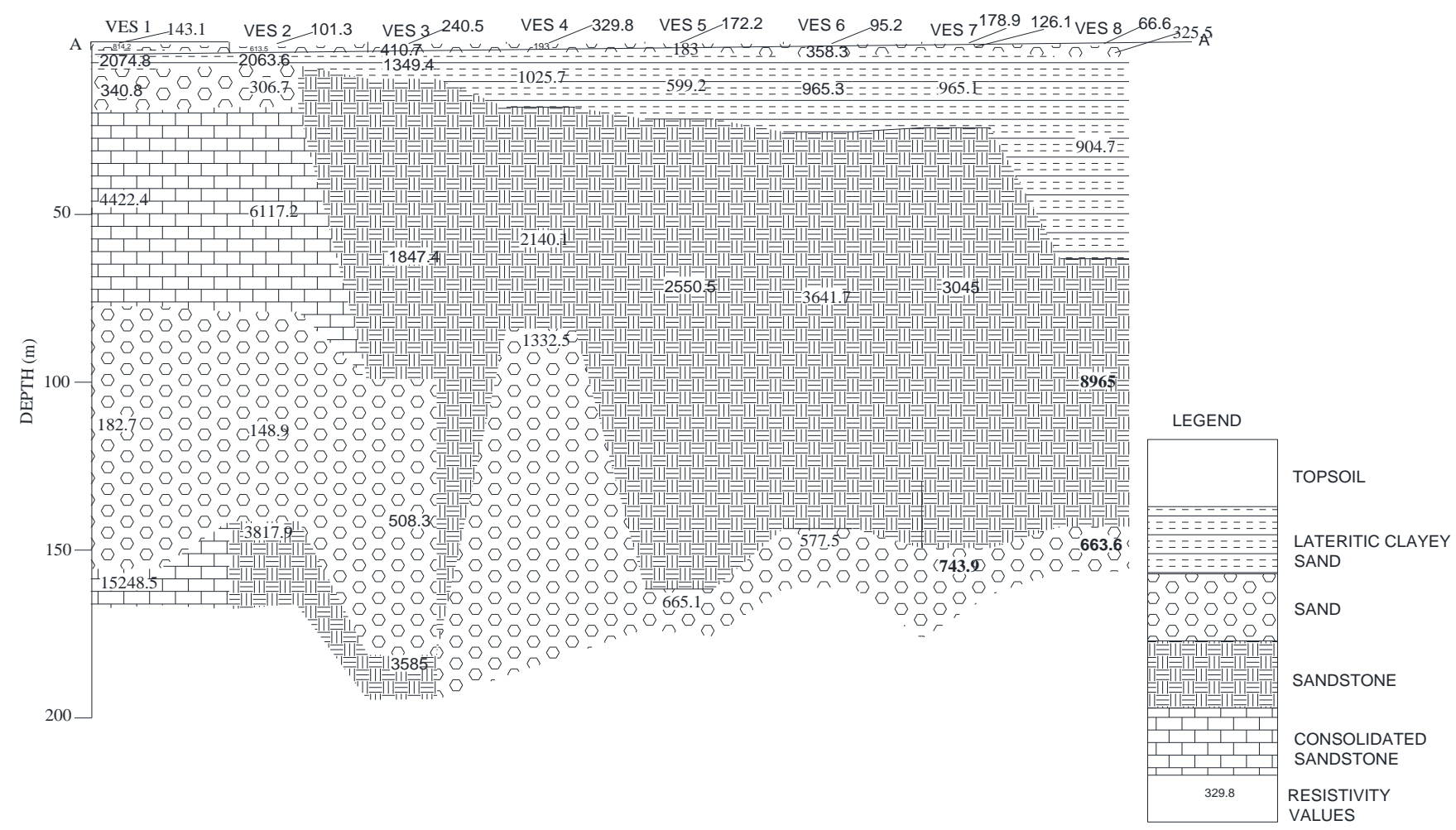

Figure 4: Geo-electric section AA' (VES 1 - 8). 


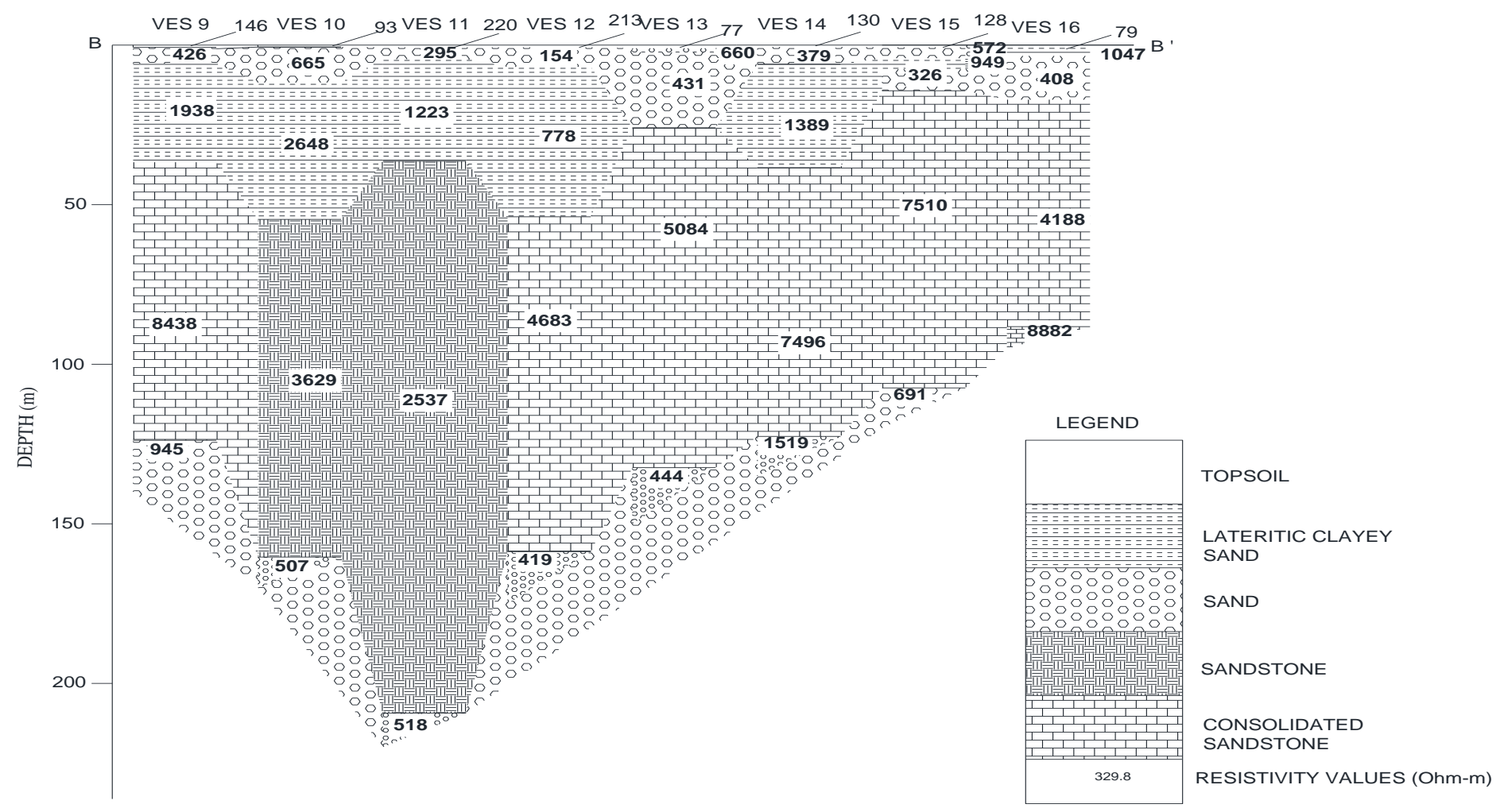

Figure 5: Geo-electric section BB' (VES 9 - 16).

The fourth geoelectric layer in VES 15 indicates sand with resistivity value and layer thickness of $325.8 \Omega \mathrm{m}$ and 6.7 $\mathrm{m}$ respectively. The fifth stratum denotes sand in VES $9-13$ with resistivity values ranging from 418.7-945.0 $\Omega \mathrm{m}$, but the thickness could not be determined due to the termination of current within that zone. This zone can be a possible aquifer in the study area. The fifth layer in VES 14 represents dry sand with resistivity value $1518.7 \Omega \mathrm{m}$, layer thickness could not be determined due to the current terminating within the region.

The fifth stratum in VES 15 and 16 depicts consolidated sandstone with resistivity values of 7510.2 and $8882.3 \Omega \mathrm{m}$ respectively and layer thickness $93.1 \mathrm{~m}$ in VES 15, layer thickness in VES 16 could not be determined due to the current terminating within the region. The sixth geoelectric unit reveals sand (this can be a possible aquifer in the study area) which has resistivity value of $691.4 \Omega \mathrm{m}$ in VES 15 , the layer thickness could not be determined due to the current terminating within the region.

\section{Geo-electric Section CC'}

The geoelectric section CC' (Figure 6) consists of VES $17-24$. This section is underlain by five geoelectric layers. These are topsoil, lateritic clayey sand, sand, sandstone and consolidated sand. The topsoil is characterized by resistivity values ranging from 60.8 to $245.1 \Omega \mathrm{m}$ with layer thickness of 0.6 to $0.8 \mathrm{~m}$. The second horizon represents sand with resistivity values ranging from 149.8 to $701.7 \Omega \mathrm{m}$ with layer thickness of 5.6 to $11.3 \mathrm{~m}$. The third geoelectric unit depicts lateritic clayey sand with resistivity values ranging from 1238.9 to $3487.5 \Omega \mathrm{m}$ with layer thickness of 30.6 to $64.1 \mathrm{~m}$.

The forth stratum denotes sandstone in VES 17 and VES 22 with resistivity values $2379.1 \Omega \mathrm{m}$ and $3347.6 \Omega \mathrm{m}$ with layer thickness of $143.4 \mathrm{~m}$ and $213.6 \mathrm{~m}$ respectively while in VES 18, 19, 20, 21, 23 and 24 it denotes consolidated sandstone with resistivity values ranging from 4130.2 12276.7 $\Omega \mathrm{m}$ and layer thickness of $74.2-153.6 \mathrm{~m}$. The fifth layer depicts sand in VES 17, 18, 19, 21, 23 and 24 (this can be a possible aquifer in the study area) with resistivity values ranging from $551.9-940.0 \Omega \mathrm{m}$, the sand in VES 22 is dry with resistivity value of $1548.5 \Omega \mathrm{m}$. The fifth layer in VES 20 depicts sandstone with resistivity value of $2026.2 \Omega \mathrm{m}$. The layer thickness could not be determined due to the termination of current in that zone. 


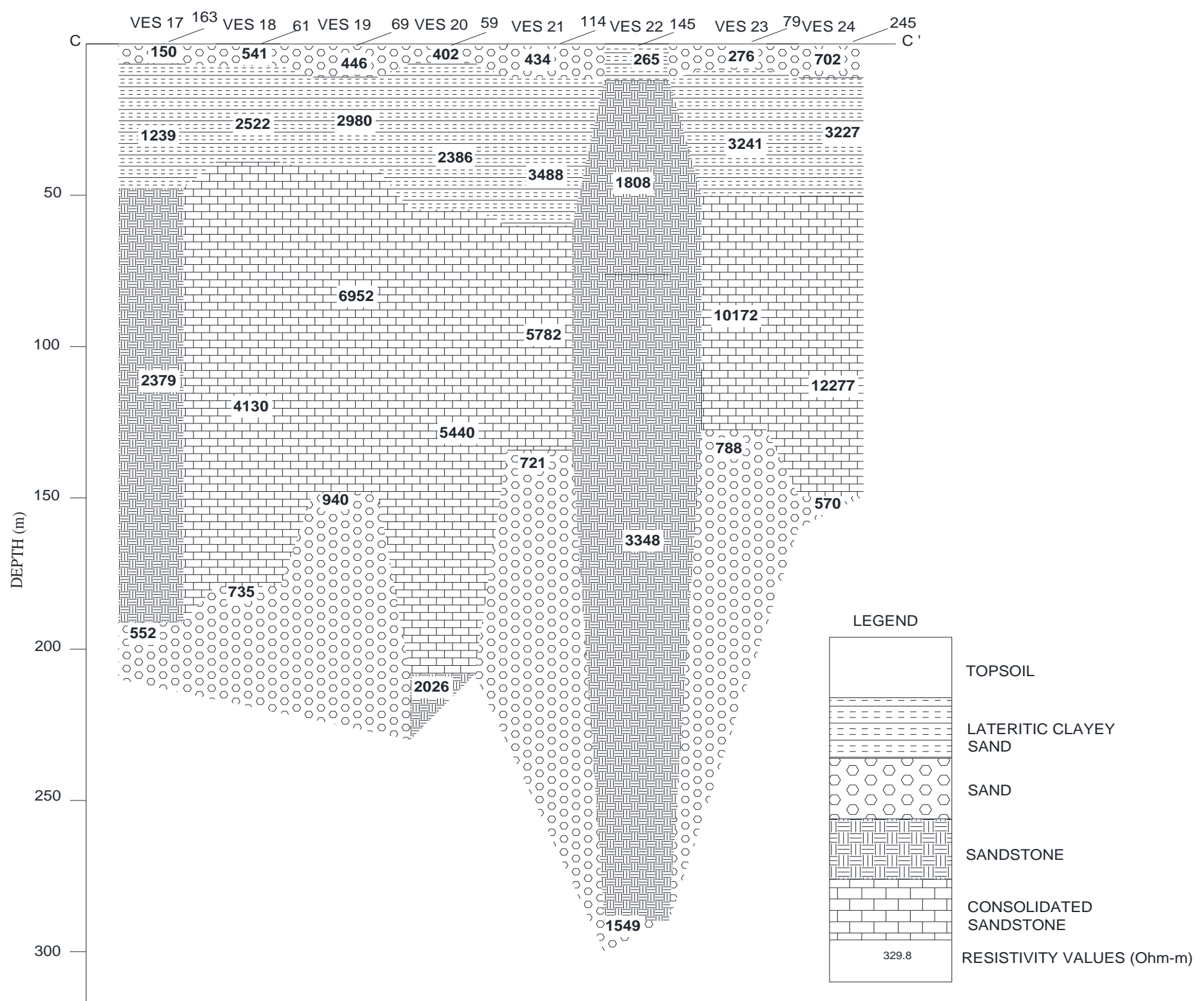

Figure 6: Geo - electric section CC' (VES 17 - 24).

\section{Geo-electric Section DD'}

The geoelectric section DD' accommodates VES 25 - 32 (Figure 7). This section has five to six geoelectric layers which comprises of topsoil, lateritic clayey sand, sand, sandstone and consolidated sandstone. The topsoil is characterized by resistivity values ranging from 111.9 to $335.5 \Omega \mathrm{m}$ with layer thickness of 0.6 to $0.9 \mathrm{~m}$.

The second stratum denotes lateritic clayey sand with resistivity values ranging from 356.0 to $2368.6 \Omega \mathrm{m}$ and layer thickness of 1.4-7.1 m. The third horizon depicts lateritic clayey sand with resistivity values ranging from 816.9 to $2077.0 \Omega \mathrm{m}$ and layer thickness of 20.6 to $49.4 \mathrm{~m}$ in VES 27, $28,29,30,31$ and 32 . The third stratum in VES 25 and 26 is indicative of sand with resistivity value $824.2 \Omega \mathrm{m}$ and 706.4 ohm-m and layer thickness 23.4 and $10.8 \mathrm{~m}$ respectively. The fourth geoelectric unit connotes sandstone in VES 25-30 having resistivity values ranging from $1747.5-3712.9 \Omega \mathrm{m}$ with layer thickness of 61.0-158.7 m while in VES 31 and
VES 32 the geoelectric layer connotes consolidated sandstone with resistivity value of $5147.4 \mathrm{ohm}-\mathrm{m}$ and $8480.3 \mathrm{ohm}-\mathrm{m}$ and layer thickness of $110.5 \mathrm{~m}$ and $68.7 \mathrm{~m}$ respectively.

The fifth geologic unit represents dry sand in VES 25, 27,30 and 31 with resistivity values ranging from 1088.6 1503.1 $\Omega \mathrm{m}$, layer thickness could not be determined in the region due to current termination. The fifth stratum for VES 28, 29 and 32 corresponds to sand (this may be a possible aquifer in the study area) with resistivity values of 519.7 $758.7 \Omega \mathrm{m}$, the layer thickness could not be determined due to the current terminating within the region. The fifth layer in VES 26 denotes sandstone with resistivity value $6028.2 \Omega \mathrm{m}$ and thickness of $149.8 \mathrm{~m}$. The sixth horizon represents sand (this may be a possible aquifer in the study area) in VES 26 with resistivity value of $867.6 \Omega \mathrm{m}$, the layer thickness could not be determined due to the current being terminated. 


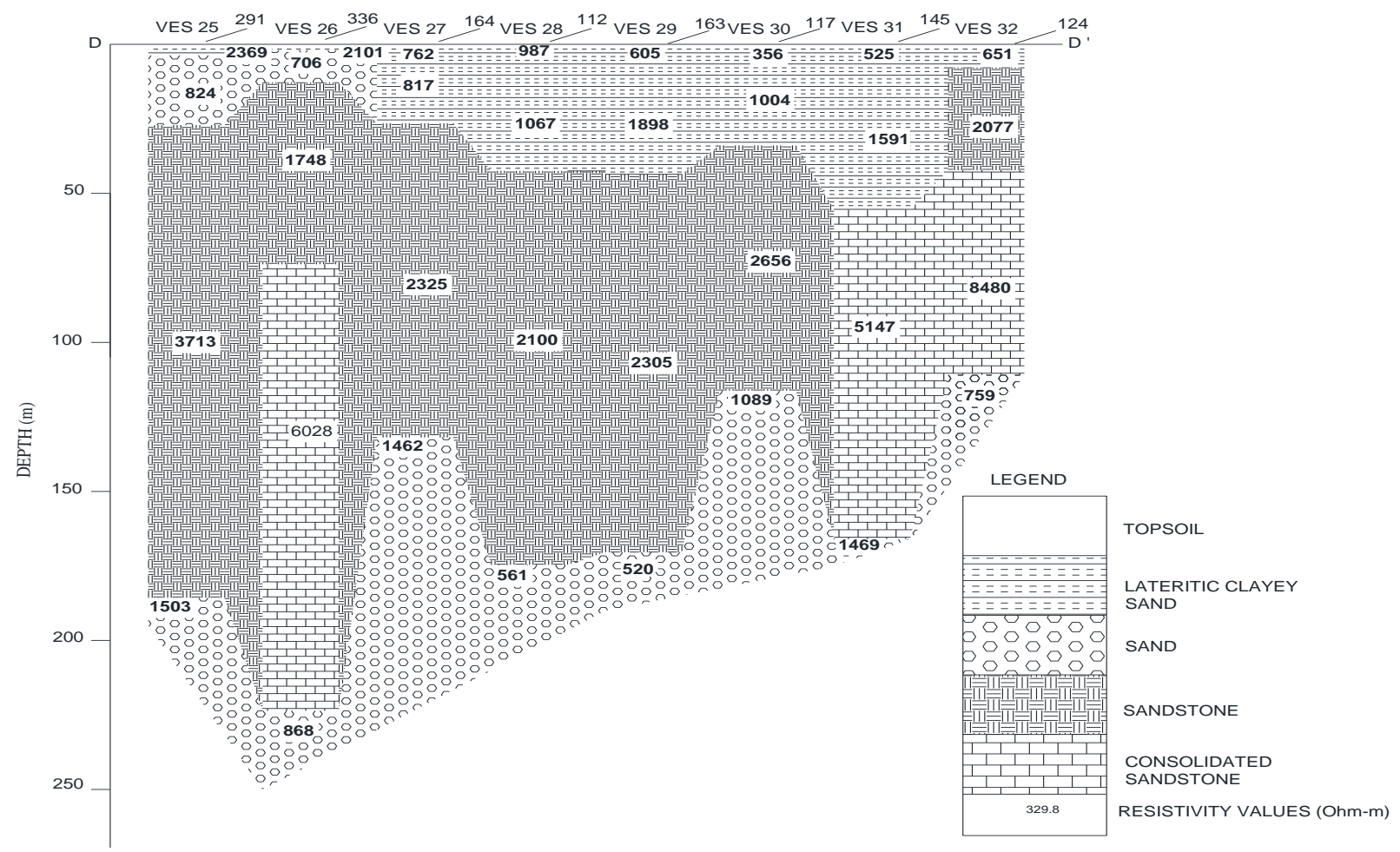

Figure 7: Geo-electric section DD' (VES 25 - 32).

\section{E. Geo-electric Section EE,}

The geoelectric section EE' comprises VES 33 - 40 (Figure 8). The section is underlain by the topsoil, lateritic clayey sand, sand, sandstone and consolidated sandstone.

The topsoil is characterized by resistivity values ranging from 42.4 to $310.3 \Omega \mathrm{m}$ and layer thickness of $0.5-0.7 \mathrm{~m}$. The second layer denotes lateritic clayey sand with resistivity values ranging from 67.7 to $1420.4 \Omega \mathrm{m}$ and layer thickness of 1.8-7.8 $\mathrm{m}$. The third stratum represents lateritic clayey sand with resistivity values ranging from 514.5 to $1567 \Omega \mathrm{m}$ and layer thickness 3.2-29.6 m while in VES 38 the layer depicts sandstone with resistivity value $1283.9 \Omega \mathrm{m}$ and layer thickness of $14.4 \mathrm{~m}$. The fourth horizon represents sandstone along VES 35, 36, 37, 38 and 39 with resistivity values ranging from $1524.9-3810.0 \Omega \mathrm{m}$ and layer thickness of 43.3 - $86.7 \mathrm{~m}$, though layer thickness in VES 39 could not be ascertained because the current terminated within this zone. In VES 33 and VES 34 the fourth stratum depicts consolidated sandstone with resistivity value of $7028.6 \Omega \mathrm{m}$ and $5249.1 \Omega \mathrm{m}$ and layer thickness of $48.5 \mathrm{~m}$ and $50.6 \mathrm{~m}$ respectively while in VES 40, the fourth layer is sand with resistivity value $486.6 \Omega \mathrm{m}$ and layer thickness $20.0 \mathrm{~m}$.

The fifth horizon for VES 33-35 is sand (this can be a possible aquifer in the study area) having resistivity values ranging from 397.9 to $552.4 \mathrm{ohm}-\mathrm{m}$ layer thickness could not be determined because the current terminated within this horizon. The fifth geoelectric unit in VES 36,37 and 38 depicts sandstone with resistivity values ranging from 3558.4-3720.6 $\Omega \mathrm{m}$ with layer thickness $53.1 \mathrm{~m}-106.8 \mathrm{~m}$. The fifth layer in VES 40 depicts consolidated sandstone with resistivity value of $7833.5 \Omega \mathrm{m}$ and layer thickness $192 \mathrm{~m}$.

The sixth geoelectric unit connotes sand (this can be a possible aquifer in the study area) in VES 36 and VES 37 with resistivity values of 508.1 and $357.4 \Omega \mathrm{m}$ respectively. The layer thickness could not be determined because the current terminated within this horizon. In VES 40, the geologic unit is representative of dry sand with resistivity value $1038.9 \Omega \mathrm{m}$. The thickness could not be determined because the current terminated within the horizon.

\section{CONCLUSION AND RECOMMENDATION}

Groundwater potential assessment was carried out in Ewuloja and its environs, Simawa, Ogun state, SouthWestern, Nigeria. Forty (40) vertical electrical soundings (VES) were used to identify potential groundwater bearing zones capable of sustaining economic development and population growth of the study area.

The interpreted results of VES data constrained by borehole information were presented as geoelectric sections. Four to seven geoelectric layers were delineated which 


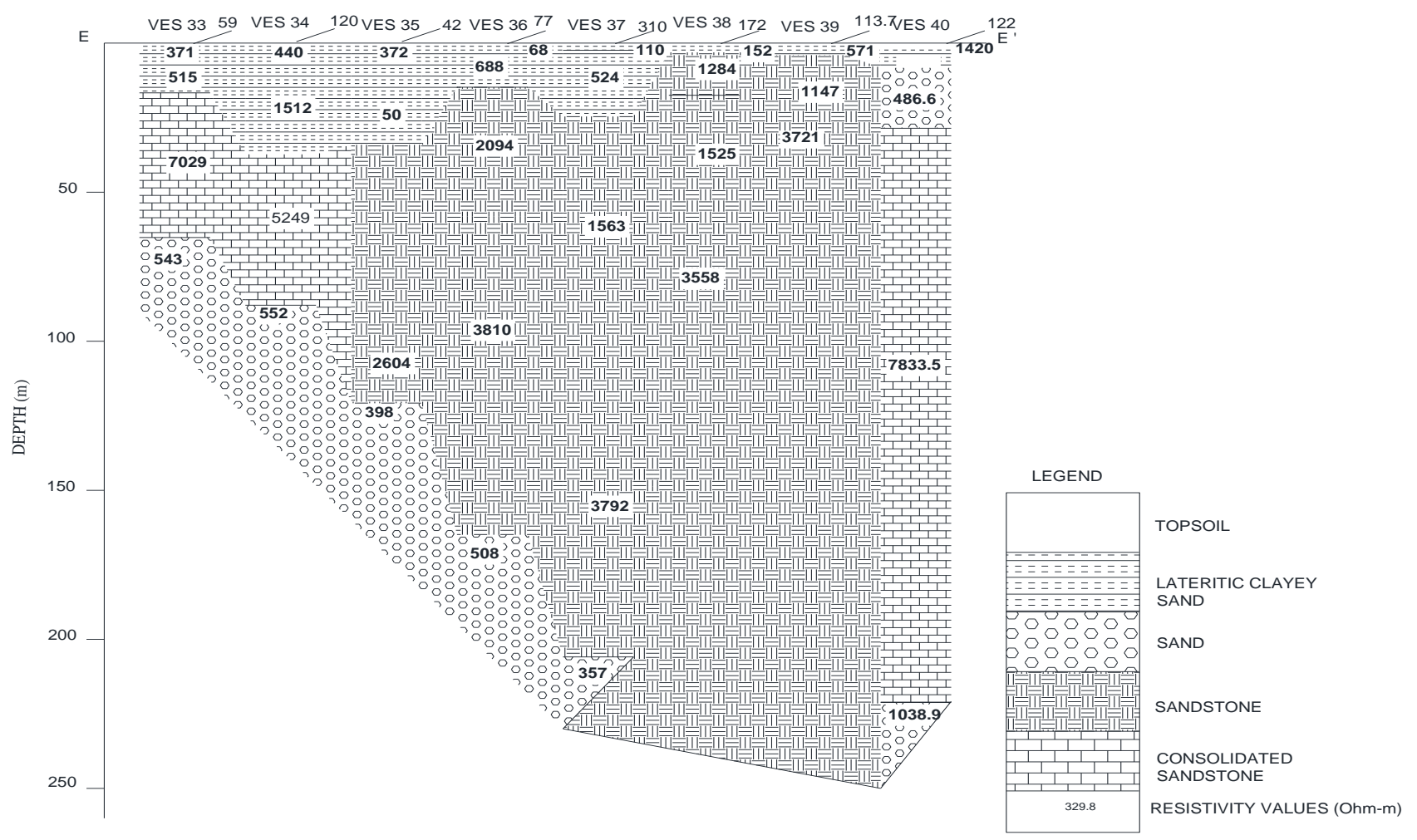

Figure 8: Geo-electric section EE' (VES 33 - 40).

correspond to topsoil, lateritic clayey sand, sandstone and consolidated sandstone.

The resistivity value of the Topsoil varies from 42.4 to $335.5 \Omega \mathrm{m}$ while its thickness varies from $0.5 \mathrm{~m}-1.0 \mathrm{~m}$. The Lateritic clayey sand has resistivity value that varies from 67.7 to $2368.6 \Omega \mathrm{m}$ while its thickness varies from $1.4-60.1$ $\mathrm{m}$. Sand has resistivity values that vary from 143.1 to $1,548.5$ $\Omega \mathrm{m}$. The resistivity of Sandstone varies from $1,332.5$ to $3,817.9 \Omega \mathrm{m}$. The thickness variation could not be ascertained at certain areas because the current terminated thereat. Consolidated sandstone has resistivity value which varies from $4,130.2 \Omega \mathrm{m}$ to $15,248.5 \Omega \mathrm{m}$ while the thickness range could not be determined due to current termination thereabout.

The analysis reveals that sands at the upper layer within the depth of $2.3-76.2 \mathrm{~m}$ are unsaturated while sands at depth not less than $100 \mathrm{~m}$ in VES 1 - VES 3, VES 5 - VES 13, VES 15, VES 17 - VES 19, VES 21 - VES 24, VES 26, VES 28, VES 29, VES 32 - VES 37 are saturated and denote the prospective zones for water accumulation in the study area. Thus, the borehole drilling could be carried out along the traverses at depth interval of between $150-210 \mathrm{~m}$.

The results affirm the effectiveness of electrical resistivity method in prospecting for ground water.

\section{ACKNOWLEDGEMENT}

The authors wish to thank the management and staff of Lukado Consult Nigeria Limited, Lagos, for providing the field equipment.

\section{REFERENCES}

Adediran, S. A.; O. S. Adegoke and I. O. Oshin. (1991). The Continental Sediments of the Nigerian Coastal Basin. Journal of African Earth Sciences (and the Middle East), 12(1-2): 79 - 84.

Alabi, A.; R. Bello, A. S. Ogungbe and H. O. Oyerinde. (2010). Determination of Groundwater Potential in Lagos State University, Ojo using Geoelectric Methods (Vertical Electrical Sounding and Horizontal Profiling). Report and Opinion, 2(5): 68 - 75.

Batayneh, A. T. (2009). A Hydrogeophysical Model of the Relationship between Geoelectric and Hydraulic Parameters, Central Jordan. Journal of Water Resources and Protection, 1 (6): 400 - 407.

Bayewu, O. O.; M. O. Oloruntola, G. O. Mosuro and A. C. Osho. (2012). The Resistivity and Electromagnetic Survey for Groundwater Evaluation in Part of Ago-Iwoye, Southwestern Nigeria. International Journal of Advances in Science and Technology, 5 (1): 87 - 99.

Ezeh, C. C. and Ugwu, G. Z. (2010). Geoelectrical Sounding for Estimating Groundwater Potential in Nsukka Local Government Area, Enugu State, Nigeria. International Journal of Physical Science, 5 (5): 415 - 420.

Iserhien-Emekeme, R. E.; E. A. Atakpo, O. L. Emekeme and O. Anomohanran. (2004). Geoelectric Survey for Ground Water in Agbede, Etsako West L.G.A., Edo State. Advanced Natural Applied Scientific Research, 2 (1): $65-72$. 
Jones, H. A. and Hockey, R. D. (1964). The Geology of Part of Southwestern Nigeria. Geological Survey of Nigeria, Bulletin 31: 1-101.

Loke, M. H. (2010). Rapid 2-D Resistivity and IP Inversion using the Least-Squares Method. Geoelectrical Imaging 2D and 3D Geotomo Software, Penang Publishers, Malaysia.

Nton, M. E.; P. R. Ikhane and M. N. Tijani. (2009). Aspects of Rock-Evaluation Studies of the MaastrichtianEocene Sediments from Subsurface in the Eastern Dahomey Basin, Southwestern Nigeria. European Journal of Scientific Research, 25 (3): 417 - 427.

Olowofela, J. A.; V. O. Jolaosho and B. S. Badmus. (2005). Measuring the Electrical Resistivity of the Earth using a Fabricated Resistivity Meter. European Journal of Physics, 26 (3): 501-515.

Omatsola, M. E. and Adegoke, O. S. (1981). Tectonic Evolution and Cretaceous Stratigraphy of the Dahomey Basin. Journal of Mining and Geology, 18 (1): 130 - 137.

Omosuyi, G. O.; A. Adeyemo and A. O. Adegoke. (2007). Investigation of Groundwater Prospect using Electromagnetic and Geoelectric Sounding at Afunbiowo, near Akure, Southwestern Nigeria. Pacific Journal of Science and Technology, 8 (2): 172 - 182.

Rosen, S. and Vincent, J. R. (1999). Household Water Resources and Rural Productivity in Sub-Saharan Africa: A Review of the Evidence. Cambridge Development Discussion Paper No. 673. Paper presented at Harvard Institute of International Development, Harvard University, Cambridge, MA, U.S.A.

Salami, B. M. and Olorunfemi, M. O. (2014). Hydrogeophysical Evaluation of the Groundwater Potential of the Central Part of Ogun State, Nigeria. Ife Journal of Science, 16 (2): 291 - 299.

World Water Organization. (2010). Water Facts \& Water Stories from Across the Globe. Available online at: http://www.worldforum.org/water_facts.php. Accessed on June 16, 2015.

WHO / UNICEF. (2000). Global Water Supply and Sanitation Assessment. Joint Monitoring Programme for Water Supply and Sanitation. World Health Organization, New York, U.S.A. 